\title{
INNOVATIONS \\ Developing an electronic information service in an academic library
}

\author{
By Amy Chang \\ Head of Access Services \\ Texas Tech University
}

In May 1989, the E-mail system for interlibrary loan at the Texas Tech University Libraries began functioning. A year later, it was linked with BookNet, a local liaison program, and an electronic bulletin. Together, these computer programs perform as the Electronic Library Service. This system provides a convenient way for faculty and students to request articles and books via ILL for material not found in the library collection, to recommend titles for purchase, to locate the liaisons of their departments, to request library instruction, and to find information about library schedules and services, from their homes or offices, any time of the day or night.

The Academic Computer Network of Texas Tech University is the Ethernet coaxial cablebased network, which offers faculty and students an excellent telecommunications network. The campus computing system uses Digital Equipment Corporation's VAX 8650 and VAX 11/780. The VAXcluster is connected to several computer networks, enabling users to access BITnet, Intnet, and EDUnet. VAX users are able to communicate with colleagues in other universities within Texas, throughout the country, and outside of the United States. THEnet, VAX-Mail, and TECH-Mail are the local network systems. All buildings on campus are networked. Several VAX terminal rooms are distributed around campus, and hard-wired terminals and dial-up terminals are distributed among departments, colleges, and dormitories. Each department can sub-assign access to its faculty and students.

\section{How it works}

The Electronic Library Service is a programmed system. After logging onto the VAX, a user is able to access the system by entering the assigned command at the Digital Equipment prompt sign. The first screen displays an introduction to the system, its purpose, and its scope. Then the user can choose to read the instructions, which explain the function keys and how the systern performs. Users who have learned the instructions can skip this screen. A short form is then displayed for users to fill out name, department, status, and VAX number. The main menu follows the short form. Five options are available: Interlibrary Loan, BookNet, Liaison Program, Library Bulletin, and Exit.

Interlibrary loan. The submenu for the interlibrary loan service offers request forms for books, articles, and dissertations, as well as requests for renewal and status checking. Questions and answers about ILL service can be displayed on the screen. ${ }^{1}$ This electronic service, combined with daily delivery of borrowed materials, offers a most useful and efficient service to TTU faculty. In addition, records for the borrowed materials are stored onto a database. At the end of each semester, reports can be generated for faculty and graduate students that provide bibliographic information for each title. ${ }^{2}$

BookNet. BookNet, the second option on the Electronic Library Service, enables the user to suggest titles for purchase and to make comments about their potential usefulness for teaching or 
research. These requests are seriously considered by collection development librarians. The order form is programmed onto the BookNet.

Liaison Program. A liaison is a librarian appointed to one or more departments according to his or her subject background. This program exists to utilize the librarian's skill and knowledge in enlarging services to faculty and students and maximizing use of the library's collections and services. Liaisons are responsible for providing user instruction, preparing bibliographies, performing online database searches, and developing assigned areas of the collection.

Because of the varied commitments that both librarians and teaching faculty have, communication between them by telephone or campus mail could take hours or even days, without the connec-

\section{Audiovisual Policies in College Libraries published}

Audiovisual Policies in College Libraries, CLIP Note \#14 is the newest addition to the CLIP (College Library Information Packet) Note series, published by ACRL.

The report is the result of a survey of small college and university library audiovisual policies. More than a dozen complete policies covering topics such as brochures, circulation policies, collection development, copyright, rentals, gifts, rates and user guides are included.

Audiovisual Policies in College Libraries was compiled by Kristine Brancolini, head of Media Services, Indiana University Libraries, under the auspices of the ACRL College Library Section's CLIP Notes Committee. The 152page paperback, printed on acid-free paper (ISBN: 0-8389-7495-3), sells for $\$ 19.95$ ( $\$ 16.95$ to ACRL, members). ALA members receive a $10 \%$ discount.

Other CLIP Notes in the series include: $\mathrm{Col}$ lege Library Newsletters, CLIP Note \#13; Performance Appraisal in Academic Libraries, CLIP Note \#12; Collection Development Policies, CLIP Note \#11; Annual Reports for College Libraries, CLIP Note \#10; Friends of College Libraries, CLIP Note \#9; Periodicals for College Libraries, CLIP Note \#8; Managing Student Workers in College Libraries, CLIP Note\#7; Mission Statementsfor College Libraries, CLIP Note \#5.

Copies of the CLIP Notes may be ordered from the ALA Order Services Department, 50 E. Huron St., Chicago, IL 60611-2795. Orders may also be taken by phone: ( 800 ) $545-2433$; or fax: (312) 440-9374. tion provided by the online Liaison Program. It enables faculty and students to identify the liaison of their respective departments and to leave messages. When the user presses 3 on the main menu of the Electronic Library Service, a list of the colleges is displayed on the screen. After the user selects a college, the system brings up a list of departments within that college and the liaisons assigned to them. The user then can choose to leave a message for the liaison or to go back to the main menu.

Library Bulletin. A submenu for the Bulletin includes the library schedule, library announcements, and library services. The schedule displays library hours, including holidays. Librarians can use the Bulletin to make announcements about bibliographic instruction, exhibitions, new services, or new electronic products. The VAX user is able to locate this information from a terminal or a personal computer with a modem any time of the day or night.

\section{Structure of the program}

The program structure of the Electronic Information Service is shown in Figure 1. Since the system needs the interactive processing option and the capability of screen design and display of the data on the screen, COBOL was chosen for the program language.

- An index file is created for storing information about the patron (the short form on the system) at the same time the information is first entered. The user's social security number is the key field for indexing. This electronic file allows the computer to retrieve the record of a patron and read it onto the output file. Whenever a social security number is entered on the short form, the computer is instructed to search the index file for that number. If it is retrieved from the file, the user need not complete the form. The index file can be stored until a decision is made to build a new file.

- Staff can enter a single command on a VAX terminal or a microcomputer with a modem to receive hard copies of electronic requests. A program instructs the VAX to sort the requests, first by patron and then by type, and to print the sorted requests. After a hard copy is printed, the electronic record is deleted automatically. The operations for reading, sorting, printing, and deleting files were programmed using the VAX Digital Command language.

- The executed program and data are also received and stored in a separate file. The programs are coded, modified, and compiled in the "home" area. This separates the executed program and data file from the coded and compiled programs and other files, which makes it easier for staff to read data and monitor the system being used. 


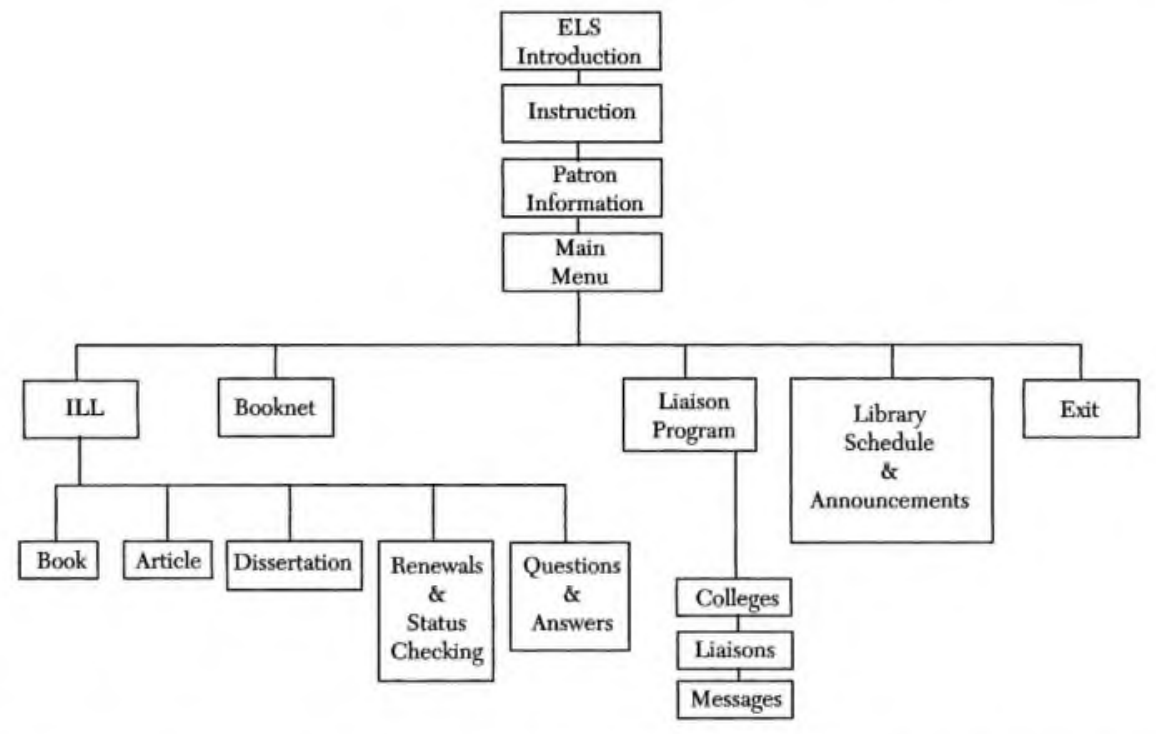

Figure 1.

- The program was designed to display the main menu after the short form; as a result, the user does not need to give information about himself for every request, as would be necessary for requests on paper. After the user fills out the request form, the system will bring either the submenu or the main menu to the screen if the user wishes to make another request. The programs for the request output (ILL, BookNet, and message to the liaison) instruct the computer to read and write the short form on each request.

- The announcement for the Library Bulletin is written on a separate file. The computer is instructed to read the file and display it on the screen. Since the file is not written within the program, the file for the bulletin can be updated anytime without interrupting the program.

- The output for ILL, BookNet, and the liaison program were formatted and programmed separately. For example, on the ILL request there is space for patron and title information; then follows a field for "Office Use Only," which allows staff to record OCLC and ILL number, locations, and the date the request was processed. For the BookNet request, the verification details, such as checklists for OCLC, BIP, price, date, etc., are formatted on each request.

- Requests for other services can be programmed in the same manner. For example, faculty and students can apply electronically for a study carrel.

- The system does not have editing capabilities, so far. Moving the cursor from one field to the previous field is not possible. In order to make corrections (e.g., for typing errors), the user will need to complete the form, then enter the number of the field that needs to be corrected. When the user enters that number, the computer is instructed to bring the cursor to that field, where the user can retype the data. The backspace key can be used for moving the cursor in the same field only.

\section{Conclusion}

The Electronic Library Service makes the library more aware of and more responsive to user demands and needs. ELS offers an easy and efficient way to communicate with library users. Messages can be sent to and from home or office at any time. This customized electronic system is recommended for the academic library that has a local network system.

Designing and implementing a small scale computer system imparts an exciting sense of accomplishment in terms of services. It not only enhances and improves the services offered by the library but also increases the library's visibility.

${ }^{1}$ Amy Chang, "Computerize Communication for Interlibrary Loan," College and Research Libraries 50 (December 1989):992-994.

${ }^{2}$ Chang, "A Database Management System for Interlibrary Loan," Information and Technology Libraries 9 (June 1990):135-143. 


\section{Institutional Data Available for Academic Libraries}

John Minter Associates, Inc. (Boulder, Colorado) has provided several useful data compilations for academic librarians. Using the National Center for Education Statistics (NCES) Integrated Postsecondary Education Data System (IPEDS) library data for 1988 (the most recent data available) Minter has produced print and machinereadable volumes containing institutional data for academic libraries in private and public two and four-year institutions as well as statistical norms. The following products are available:

- 1988 Academic Library Survey Response. Two volumes of library-by-library statistics on collections, expenditures, staffing, interlibrary loan, and library services. Volume one contains data for public institutions; volume two contains for private institutions. Both are organized by state. Each volume costs $\$ 39$. These print volumes are also available as machine-readable files (Lotus 1-2-3 files are \$79/volume; ASCII and .DBF files are $\$ 69 /$ volume.)

- Statistical Norms for College \& University Libraries, 2nd ed. Norms are presented for groups based on the Carnegie Foundation's Classification. Ratios such as library expenditures as a percentage of educational and general expenditures, expenditures for current serials per FTE students, total operating expenditures per FTE student are just a sample of the 154 items reported for each norm group. Statistical Norms costs $\$ 59$ for the print volume; $\$ 79$ for a disk copy in Lotus 1-2-3, DBase, or ASCII files.
- Library Management Ratios Calculator. Although it is necessary to first key in the data, the Calculator is a self-running program that will automatically calculate 150 management ratios. The Calculator can be used to look at your own data, previous year's data, or data from institutions you consider in your peer group. The Calculator requires an IBM-PC compatible with a high density disk drive or hard disk and sells for $\$ 55 ; \$ 35$ if ordered with one of the other publications.

These publications may be ordered from John Minter Associates, Inc., 2400 Central Avenue, B-2, Boulder, CO 80301; (800) 444-8110; fax: (303) 449-1351.

The 1988 Academic Library Survey Response volumes are useful supplements to the NCES report Academic Libraries, 1988 that provides summary statistics for the nation and individual states. The data are organized by highest degree offered and by level of control. The data are available in print (copies are free while supplies last), on high density tape (\$175) or high density diskette $(\$ 75)$ and may be ordered from NCES Information Services (800) 424-1616; U.S. Department of Education, Information Technology Branch, 555 New Jersey Ave., NW, Washington, DC 20208-5725.

What distinguishes Minter's work from the volume available from NCES is Minter's provision of library-by-library data and the presentation of 154 statistical norms. If you want data about a specific institution Minter's publications will prove invaluable because NCES will not be publishing this institution-specific data.

\section{Diversity initiatives}

In February, Ford Foundation president Franklin A. Thomas and a panel of national education leaders announced a new program of grants to improve race relations and foster cultural and intellectual diversity in undergraduate colleges and universities. Responding, in part, to incidents of racial and religious intolerance and sexual harassment, the program is rooted in the conviction that teaching and learning ultimately define campus culture.

As part of the new initiative, the foundation recently awarded grants totaling $\$ 1.6$ million to 19 colleges and universities, primarily for faculty development and the design or revision of courses. The grants are aimed at encouraging colleges to broaden the scope of reading and instructional materials used in courses that fulfill general educa- tion, distribution, or departmental requirements. The programs funded include new or revised courses for students, seminars for faculty, and student debates and research. Some programs also include artistic and cultural activities.

The grantees, chosen competitively from a pool of 106 invited proposals, are: Bemidji State University, Boston College, Brandeis University, University of California-Los Angeles, Denison University, Haverford College, University of Iowa, Millsaps College, Mount St. Mary's College, New School for Social Research, University of Notre Dame, Pitzer College, University of Redlands, University of Rochester, Southwest Texas State University, Spring Hill College, Tulane University, Virginia Commonwealth University, and Wesleyan University. 